\title{
La historia en la enseñanza del ADN: Una propuesta para generar un cambio de visión de ciencia en la escuela
}

\author{
The history in DNA: A proposal to generate a change \\ of vision of science in school
}

\section{Leonardo A. Cortez ${ }^{1 \mathrm{ac}}$, Nubia P. Latorre ${ }^{1 \mathrm{bc}} \&$ Rubinsten Hernández ${ }^{\text {1d }}$ \\ ${ }^{1}$ Fundación Universidad Autónoma de Colombia, Bogotá, Colombia.}

a Licenciado en Biología, Universidad Pedagógica Nacional. Docente de Biología Colegio Alemania Solidaria IED. 'bicenciada en Química, Universidad Pedagógica Nacional. Docente de Química Colegio El Porvenir IED. 'Estudiante de Maestría en Didáctica de las Ciencias, Fundación Universidad Autónoma de Colombia. ${ }^{\mathrm{D}}$ Docente investigador, Fundación Universidad Autónoma de Colombia.

Recibido: $18-09-15$

Aprobado: 04-01-16

\section{*Correspondencia}

Email: leopechan@gmail.com

\section{Citar como:}

Cortez, L., Latorre, N., \& Hernández, R. (2016). La historia en la enseñanza del ADN: Una propuesta para generar un cambio de visión de ciencia en la escuela. Propósitos y Representaciones, 4(1), 281-326. doi: http:// dx.doi.org/10.20511/pyr2016.v4n1.91

(C) Universidad San Ignacio de Loyola, Vicerrectorado de Investigación y Desarrollo, 2016.

(๕) BY-NC-ND Este artículo se distribuye bajo licencia CC BY-NC-ND 4.0 Internacional (http://creativecommons.org/licenses/by-nc-nd/4.0/). 


\section{Resumen}

Actualmente, en la enseñanza de las ciencias, y en el caso particular de las ciencias naturales, hay conceptos a nivel escolar que presentan un elevado nivel de abstracción. Conceptos tales como átomo, gen, mol y energía, entre otros, se dificulta llevarlos al aula de una manera accesible y comprensible para los estudiantes. Esta situación requiere que el docente diseñe estrategias alternativas que favorezcan aprendizajes significativos. Dar prioridad a la enseñanza de conceptos en ciencias promueve la concepción de ciencia como un constructo terminado, infalible, ajeno al contexto y que no evoluciona, tornando el aprendizaje de las ciencias como algo monótono y poco interesante para los estudiantes. De acuerdo con algunas investigaciones realizadas en la línea de historia y epistemología de las ciencias, se reconoce la pertinencia y las ventajas que tiene su inclusión para promover no solo una formación conceptual y académica, sino también para ampliar el espectro de posibilidades que permitan al estudiante transformar las concepciones de ciencia hacia un paradigma más dinámico y participativo. Reconociendo las bondades del uso de la historia en la enseñanza de las ciencias, en este texto se describe una propuesta para la enseñanza de la estructura del ADN en estudiantes de educación media en el marco de la Maestría en Didáctica de las Ciencias de la Fundación Universidad Autónoma de Colombia bajo esta perspectiva.

Palabras clave: Historia de las ciencias, ADN, enseñanza de las ciencias.

\section{Summary}

Currently, in science teaching and in particular, natural science teaching there are concepts in the school that have a high level of abstraction. Concepts, such as atom, gene, mole and energy, among others are difficult to explain in an understanding manner to students. This situation requires the teacher to design alternative strategies to promote meaningful learning. Give priority 
to teaching concepts in science promotes the conception of science as a finished, infallible construct outside the context and does not evolve; turning science learning into something monotonous and uninteresting for students. According to some researches in the line of history and epistemology of sciences, its importance and advantages are recognized to promote not only a conceptual and formal education, but also to broaden the spectrum of possibilities that allow the students to transform conceptions of science into a more dynamic and participatory paradigm. Recognizing the benefits of the use of history in science teaching, a proposal is made for the DNA structure teaching in secondary school students within the framework of the Master in Teaching of Sciences of the Fundación Universidad Autónoma de Colombia, under this perspective.

Keywords: History of science, DNA, science teaching. 


\section{Introducción}

El trabajo científico, más allá de ser considerado una posible forma de comprender el mundo que nos rodea, es una actividad humana influenciada por el contexto social, político, económico y académico en el que se desarrolla. Conocer la forma como se produce el conocimiento científico, su actividad y sus protagonistas permite generar posturas crítico-reflexivas de quienes se involucran en él (Matthews, 1994; Solbes \& Traver, 1996). Enseñar desde un enfoque histórico no solo demanda un amplio conocimiento de la disciplina por parte del docente, sino que además requiere de una sólida fundamentación epistemológica y del uso de un lenguaje específico que, más allá de incluir fechas y acontecimientos específicos, involucre estrategias para dar respuesta a situaciones históricas y poder comprender el pasado de forma diacrónica (Carrasco, Molina \& Puche 2014). Por lo tanto, la inclusión de la historia de las ciencias en los procesos de enseñanza en los diferentes niveles de escolaridad cobra cada vez mayor importancia, donde el profesor debe asumir una posición crítica y analítica que, mediante un trabajo organizado y estructurado, logre articular el plan de estudios con el desarrollo del pensamiento científico.

De otro lado, los eventos científicos se han caracterizado porque están permeados por relaciones de poder, discriminación y conflicto de intereses, entre otros aspectos. Por lo tanto, introducir en el aula elementos históricos de dichos sucesos, hechos y eventos posibilita un cambio de paradigma en la concepción de ciencia que tienen los estudiantes hacia uno más acorde con la realidad, el contexto y la sociedad.

A partir de la experiencia docente en la educación escolar básica y media, y tal como reportan algunos autores (Sáiz Serrano, 2013; Prieto, Carrasco \& Martínez, 2013; Betancur, 2008; Bugallo, 1995; Gil Pérez, 1993), es necesario introducir en el aula estrategias didácticas distintas a las tradicionales, en particular para la enseñanza de algunos conceptos biológicos 
que tienen un alto nivel de abstracción; ejemplo de ello es la estructura del ADN. En ese orden de ideas, parte del trabajo que se describe en este texto ha sido desarrollado dentro del proyecto de investigación que se adelanta actualmente con estudiantes de undécimo grado de secundaria y que tiene por objetivo la aproximación hacia la estructura del ADN desde un enfoque histórico para favorecer un cambio de paradigma sobre la naturaleza de las ciencias.

\section{Importancia de la historia en la enseñanza de las ciencias.}

En las últimas décadas se ha incrementado el número de publicaciones que hacen referencia a las ventajas educativas y didácticas del uso de la historia en la enseñanza de las ciencias, y con el surgimiento de disciplinas como la didáctica de las ciencias se ha consolidado la historia de las ciencias como línea de investigación para cualificar los procesos de enseñanza y aprendizaje en este campo. Desde esta perspectiva, la historia de las ciencias en los procesos de enseñanza favorece la determinación de obstáculos epistemológicos, la definición de contenidos de la enseñanza y la posibilidad de abrir espacios de reflexión en el aula sobre la producción, la apropiación y el control de los conocimientos a nivel individual y social (Carrasco, 2014; Martínez, Valls \& Pineda, 2009; Sáiz Serrano, 2013; Gagliardi, 1988; Gil Pérez, 1993).

El enfoque histórico también ofrece la posibilidad de visualizar hechos científicos proyectados a futuro, mostrando que la ciencia es un proceso en permanente cambio y que se encuentra permeada por factores sociales, políticos y económicos, sujetos a tensiones, crisis y retrocesos propios de la actividad humana. El momento histórico actual depende de las decisiones que se tomaron a través de la historia y, en esta medida, el futuro estará determinado por las disposiciones del presente. Este tipo de razonamientos no solo debe ser llevado al aula, sino que debe hacer parte de los procesos de formación de los docentes sin importar la disciplina específica del conocimiento de su dominio, proporcionando elementos de 
juicio que enriquezcan la actividad docente y posibiliten la introducción de una didáctica innovadora (Izquierdo, 1996). Considerar el uso de la historia en la enseñanza de las ciencias favorece también el cambio de un paradigma predominantemente positivista hacia uno que dé cuenta del carácter humano, ético y social del trabajo científico que propicie espacios de análisis y reflexión (Solbes \& Traver, 2001). En la Figura 1 se especifican otros aportes importantes del uso de la historia en la enseñanza de las ciencias.

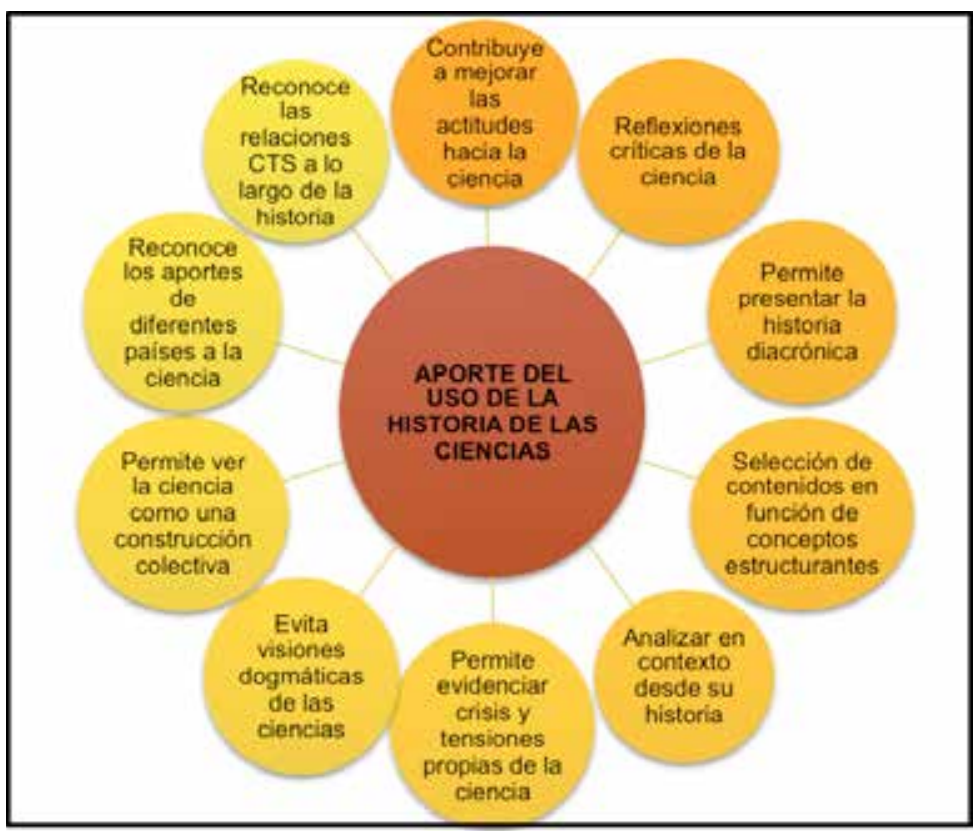

Figura 1. Aporte del uso de la historia de las ciencias en la enseñanza.

\section{Paradigmas de la ciencia.}

Uno de los aspectos que se pretende contrastar al inicio y final de la investigación es la concepción que tienen los estudiantes acerca de la ciencia, identificando sobre cuál paradigma orientan sus pensamientos, sus formas de expresión y sus acciones. Esto obedece a la necesidad de propiciar un cambio de paradigma sobre la naturaleza de las ciencias en la escuela con el objetivo de establecer la relación entre el hecho científico y su impacto 
en la sociedad que, según algunos referentes, no debe superar los 50 años, pero que la evidencia muestra que, en algunos casos, este periodo de tiempo se ha incrementado más allá de lo esperado (Merlano, 2013). Con base en lo anterior, se vio la necesidad de fundamentar epistemológicamente los paradigmas sobre la naturaleza de la ciencia que se adecuaran a la tendencia del modelo educativo colombiano para poder orientar las prácticas pedagógicas hacia aquel que, abordado desde una perspectiva histórica, se acercara más a propiciar los elementos necesarios para promover el pensamiento crítico y reflexivo en los estudiantes de un contexto determinado y, de esta forma, poder ampliar sus concepciones acerca de la ciencia. Por esto se tomó como referente epistemológico la clasificación de paradigmas de la ciencia propuesta por Vázquez, Manassero \& Acevedo en 2001, donde se proponen cuatro paradigmas que caracterizan el quehacer científico.

- Paradigma positivista: se asume la ciencia como un conjunto de verdades que se obtienen de la experimentación y el uso del método científico como mecanismo lineal, único y universal, que tiene en cuenta las magnitudes y las mediciones, para formular un conjunto de reglas que definen y controlan el mundo.

- Paradigma pragmatista: contempla la ciencia como la búsqueda de teorías verdaderas por medio de la razón, mostrando la falsabilidad de estas y buscando la verdad sobre todas las teorías existentes.

- Paradigma realista: la ciencia es vista como una herramienta que busca producir teorías capaces de superar contrastes empíricos, lo que las hace más confiables.

- Paradigma relativista: considera la ciencia como un proceso social, humano, flexible y dinámico donde el científico interacciona no solo con la razón sino también con el entorno social, político y económico que influencia su trabajo y acción.

Teniendo en cuenta estas caracterizaciones sobre la naturaleza de las ciencias, esta investigación busca, además de hacer uso de la historia en 
la enseñanza de la estructura del ADN, aproximar a los estudiantes hacia el paradigma relativista retomando algunos de los sucesos en donde se hacen evidentes momentos de tensión y crisis propios de la actividad humana en torno a la deducción de la estructura del ADN, dado que este paradigma posibilita presentar a los científicos como personas permeadas por las emociones, la sociedad y el momento histórico en el que se desarrollan sus investigaciones.

\section{Propuesta de estrategia didáctica.}

Algunas formas de introducir la historia de las ciencias en la enseñanza como estrategia didáctica son, frecuentemente, las líneas de tiempo, las biografías y los datos biográficos, entre otros, en donde muchas veces se proporciona una descripción lineal y aséptica de descubrimientos exitosos y verdades absolutas (Valcárcel, González \& Llavador, 2006; Gagliardi \& Giordan, 1986). El uso de apartados y reseñas históricas no suele ser muy recurrente en la enseñanza de las ciencias naturales debido a la complejidad y exigencia para la búsqueda de fuentes primarias y al hecho de que, de una u otra forma, se alejan del carácter anecdótico y conceptual con el que se suelen presentar hechos históricos para abordar conceptos científicos, si es que estos son tomados en cuenta. Una alternativa de introducción de la historia son las reseñas históricas que, más allá de ubicar cronológicamente hechos científicos o narrar aspectos biográficos, permiten realizar una contextualización de un suceso de importancia científica que involucra elementos sociales, políticos y económicos que amplían la visión de una ciencia que se construye de manera dinámica, no lineal y más humana, y que, articulados con otro tipo de actividades, favorecen la construcción de conceptos y el cambio de paradigma sobre la naturaleza de la ciencia.

A continuación se presenta un fragmento de la reseña histórica, eje de la estrategia didáctica de esta propuesta, diseñada y elaborada por los autores, en la que se revisaron y utilizaron tanto fuentes primarias como 
secundarias, donde se hace un recorrido que tiene en cuenta los protagonistas de la deducción de la estructura del ADN, no solo aquellos reconocidos por la historia, sino también los que contribuyeron significativamente en este estudio y que, en el momento, no tuvieron el merecido reconocimiento por su labor. De igual manera, se mencionan algunas tensiones personales y sociales que le dieron forma y sentido a un proceso no solo científico, sino también social y humano; a un suceso que partió en dos la historia de la biología.

\section{La doble hélice del ADN.}

Rosalind Elsie Franklin (1920-1958), recordada como "La dama ausente", nació en Notting Hill, Londres, el 25 de julio de 1920. Realizó sus estudios universitarios, en física, química y matemáticas, en el Newnham College, el colegio mayor femenino de la Universidad de Cambridge. Por esa época, a las mujeres de Cambridge no se les otorgaba el grado de licenciado, no se les consideraba parte del claustro y se limitaba el número de doctorandas a un $10 \%$ como mucho. Antes de trabajar con el ADN, Rosalind estudió cristales de carbón y, luego de obtener su doctorado, se especializó en la técnica de difracción de rayos X, en París. Regresó a Londres para trabajar en el King's College, dirigido por Sir John T. Randall (1905-1984), donde obtuvo la famosa fotografía 51. Junto con ella se encontraba realizando estudios sobre los cristales de ADN Maurice Wilkins (1916-2004), físico neozelandés y especialista en el estudio de los rayos X. Las relaciones entre estos dos científicos se caracterizaban por ser distantes y marcadas por la tensión tanto a nivel personal como laboral, situación que llevó a Rosalind a mantener sus progresos en la investigación al margen de su colega y del laboratorio en el que trabajaban.

Debido a las complejas relaciones entre Franklin y Wilkins en el King's College, y con el ánimo de liberar tensiones, Randall le pidió a Rosalind, a través de un comunicado displicente y autoritario, que le cediera 
su trabajo a Maurice Wilkins y abandonara el laboratorio junto con toda la investigación.

Paralelamente a los estudios realizados en el King's College, James Watson (1928), biólogo y doctor en zoología estadounidense, y Francis Crick (1916-2004), físico, biólogo molecular y neurocientífico británico, desarrollaban estudios - un tanto tímidos- frente a la estructura del ADN en el laboratorio Cavendish, en Cambridge, bajo la dirección de Sir William Lawrence Bragg (1890-1971). Watson estaba obsesionado con vencer a su compatriota, el bioquímico Linus Carl Pauling, nacido en Portland (Oregón), en la carrera por descifrar la estructura del ADN (Vicente, 2008). Esta situación lleva a Watson y Crick a realizar un estudio apresurado del ADN, proponiendo una estructura de tres hélices con la secuencia de azúcar y fosfato hacia el interior de la molécula y con una conformación de bases nitrogenadas al exterior unidas por iones de magnesio. Dicha estructura fue presentada de manera informal a Rosalind, Wilkins y Raymond Gosling (1926-2015), estudiante investigador asignado a Rosalind, quienes en noviembre de 1951 tenían los suficientes datos para proponer que el ADN era una estructura helicoidal formada por un azúcar y un grupo fosfato que se encontraban en el exterior de la molécula, y que las bases nitrogenadas deberían aparecer al interior. Esta fue parte de las fuertes críticas que recibirían, especialmente de Franklin.

Enterado de este descalabro, Lawrence Bragg les ordena a Watson y a Crick que dejen el estudio estructural del ADN a los miembros del grupo de investigadores del King's College y que vuelvan a sus tareas específicas: la estructura del virus del mosaico del tabaco con su ácido nucleico (ARN) y la estructura de la hemoglobina, respectivamente (Guevara Pardo, 2004).

En enero de 1953, y sin el conocimiento de Rosalind Franklin, Wilkins le muestra imprudentemente a James Watson la fotografía 51, obtenida a partir de la difracción de los rayos $\mathrm{X}$ de cristales de $\mathrm{ADN}$, bajo 
unas condiciones especiales de hidratación en las que se evidenciaba que la estructura del ADN obedecía a una doble hélice, situación que no había sido considerada antes y que James Watson y Francis Crick utilizan como pieza clave para proponer la estructura final de la molécula del ADN.

El 28 de febrero de 1953, Watson y Crick habían descifrado la estructura del ADN, y se dirigen a su habitual punto de esparcimiento, el pub The Eagle, al que acudían después de las largas jornadas de trabajo, y en un gesto de victoria, Crick exclama la famosa frase "...hemos encontrado el secreto de la vida...". Luego de entablar una reconciliación académica con Rosalind Franklin, los biólogos Watson y Crick envían el manuscrito de su investigación a la revista Nature, y el 25 de abril del mismo año es publicado bajo el nombre de "Molecular Structure of Nucleic Acids" en un artículo de aproximadamente 900 palabras. En la misma revista y publicación aparece un artículo de Wilkins con dos de sus colaboradores, titulado "Molecular Structure of Desoxypentose Nucleic Acids", y otro de Rosalind Franklin y Gosling, bajo el nombre de "Molecular Configuration in Sodium Thymonucleate", todos sobre la estructura molecular del ADN, confirmando que habían llegado a las mismas conclusiones (Ortiz Hidalgo, 2003).

Estas publicaciones no tuvieron el éxito esperado durante los primeros años dentro de la comunidad científica, y fue solo cuando se explicó la duplicación del ADN -durante los años 60- que, como reconocimiento a las investigaciones realizadas, se les otorgó el Premio Nobel de Fisiología y Medicina en 1962 a Watson, Crick y Wilkins. Mientras que Rosalind Franklin fallece a los 37 años, a causa de un cáncer de ovario, por lo que no alcanza a ser reconocida con el Nobel junto con sus colegas.

A continuación se presenta una propuesta didáctica de introducción de la historia de las ciencias en la enseñanza de la estructura del ADN con estudiantes de educación media del distrito capital de Bogotá (Colombia). Este 
proyecto tiene como intención contribuir a la transformación de las prácticas docentes tradicionales, en las que predomina una enseñanza conceptual y transmisionista, por aquellas que permitan a los estudiantes acceder al conocimiento de una ciencia flexible, contextualizada, humana y consciente, con el objetivo de mejorar las ideas, percepciones, concepciones y nociones que tienen los estudiantes acerca del mundo, facilitando su comprensión y acción en el mismo para promover la alfabetización científica y la formación de futuros científicos (Roca, Sanmartí \& Márquez, 2013; Deulofeu, Márquez \& Sanmartí, 2010; Sanmartí, 2000). 


\section{Tabla 1.}

Descripción de las etapas de desarrollo de la propuesta.

\begin{tabular}{|c|c|}
\hline Etapas & Descripción \\
\hline $\begin{array}{l}\text { Reconstrucción } \\
\text { histórica }\end{array}$ & $\begin{array}{l}\text { - Revisión teórica bibliográfica de fuentes primarias y secundarias de } 50 \\
\text { años antes del trabajo de Watson y Crick. } \\
\text { - } \quad \text { Selección de las fuentes más relevantes para el trabajo a desarrollar. } \\
\text { Generación de categorías de lectura y análisis de las fuentes. } \\
\text { 1. Aspectos biológicos del ADN. } \\
\text { 2. Relaciones entre ciencia, tecnología y sociedad. Tensiones sociales } \\
\text { 3. Proyección de los estudios del ADN. } \\
\text { Elaboración del documento de la reconstrucción. }\end{array}$ \\
\hline $\begin{array}{l}\text { Fundamento } \\
\text { epistemológico y } \\
\text { didáctico }\end{array}$ & $\begin{array}{l}\text { - Descripción de las condiciones a través de las cuales se ha producido el } \\
\text { conocimiento alrededor de la estructura del ADN, precisando aspectos } \\
\text { científicos y sociales. } \\
\text { Revisión de algunos de los soportes conceptuales que han marcado, de } \\
\text { manera sistematizada, la generación y construcción de conocimientos que } \\
\text { orientan la labor docente. } \\
\text { Reconocimiento de las bases conceptuales para el establecimiento de } \\
\text { la didáctica de las ciencias como disciplina científica consolidada, que } \\
\text { tiene como propósito estudiar e intervenir los procesos de enseñanza y } \\
\text { aprendizaje de un área específica del conocimiento. }\end{array}$ \\
\hline $\begin{array}{l}\text { Diseño de la estrategia } \\
\text { didáctica }\end{array}$ & $\begin{array}{l}\text { - Diseño, elaboración, validación e implementación de instrumentos de } \\
\text { diagnóstico: } \\
\text { 1. Instrumento tipo escala Likert, para la recopilación de las } \\
\text { concepciones que tienen los estudiantes acerca de la ciencia. (Ver } \\
\text { anexo A). } \\
\text { 2. Cuestionario de preguntas abiertas, basado en lectura de actualidad, } \\
\text { para identificar las concepciones alternativas que tienen los } \\
\text { estudiantes sobre el ADN y su estructura. (Ver anexos B y C). } \\
\text { - Estructura de la unidad. } \\
\text { Selección de los contendidos a trabajar: } \\
\text { 1. Reconstrucción histórica: viaje en el tiempo. } \\
\text { 2. Estructura del ADN: descifrar el rompecabezas del ADN. } \\
\text { 3. Proyección: "La química de la vida": implicaciones de la estructura } \\
\text { - } \quad \text { del ADN a nivel biológico. } \\
\text { - Gelección de las actividades y secuenciación. } \\
\text { Generación de criterios de seguimiento y evaluación. }\end{array}$ \\
\hline $\begin{array}{l}\text { Implementación de la } \\
\text { estrategia didáctica }\end{array}$ & $\begin{array}{l}\text { Esta estrategia didáctica está diseñada para ser implementada con } \\
\text { estudiantes de educación media, teniendo en cuenta los conceptos básicos } \\
\text { de genética y química orgánica que debieron ser adquiridos en los niveles } \\
\text { educativos anteriores. }\end{array}$ \\
\hline $\begin{array}{l}\text { Resultados y análisis } \\
\text { de resultados }\end{array}$ & $\begin{array}{l}\text { - } \quad \text { Formulación de criterios de seguimiento y evaluación. } \\
\text { - } \quad \text { Análisis de los instrumentos aplicados. } \\
\text { - } \quad \text { Triangulación y análisis de resultados. } \\
\text { - } \quad \text { Evaluación de la estrategia didáctica. }\end{array}$ \\
\hline
\end{tabular}




\section{Consideraciones finales}

El poder hacer uso de la historia de las ciencias para la enseñanza de conceptos como la estructura del $\mathrm{ADN}$ se convierte en una estrategia didáctica que permite no solo la comprensión y aprendizaje de conceptos propios de la ciencia, sino también realizar transformaciones en las concepciones que tienen los estudiantes acerca de la ciencia y la forma como esta ha ido evolucionando a través del tiempo, de tal forma que se acerquen a una ciencia más humana, permeada por momentos de tensiones y crisis propios de un lugar, tiempo y contexto dados que determinan y demarcan la forma en que se desarrollan y se llevan a cabo las investigaciones científicas. Incluso hoy en día la ciencia reconoce que, en un marco de cooperación y colaboración, la carrera por descifrar el rompecabezas de la estructura de la vida se habría logrado en un menor tiempo con resultados similares y donde sus protagonistas habrían tenido un reconocimiento diferente.

La introducción de la historia de las ciencias en la enseñanza de la estructura del ADN es una estrategia que no solo favorece y minimiza la fractura conceptual para la comprensión de la herencia a nivel macroscópico y microscópico, sino que posibilita el análisis de los protagonistas y situaciones de carácter social, político y económico determinantes en el momento de la deducción de la estructura del ADN. De esta forma se resalta la importancia de un aporte científico que, más allá de ser la descripción de una estructura molecular química, proporcionó la información para comprender las bases de la herencia y transmisión de las características hereditarias, posibilitando el surgimiento de disciplinas científicas como la genética molecular y la biotecnología, con múltiples aportes a la ciencia y que, llevada al aula, favorece la generación de procesos científicos y promueve espacios de análisis y reflexión sobre sus implicaciones científicas y éticas.

Poder establecer los fundamentos epistemológicos y didácticos fortalece los procesos de investigación encaminados a generar transformaciones 
de fondo en la práctica docente a partir de propuestas de intervención viables, contextualizadas y que respondan a las necesidades educativas actuales. Esto ha sido posible al tomar como referentes a autores como Carraco (2014), Borgui (2010), Matthews (1994), Solbes y Traver (1996), quienes han desarrollado estrategias a partir del uso de la historia de las ciencias en la enseñanza de diferentes disciplinas científicas que incluyen la biología, la química y la física, entre otras, y que proporcionan elementos teóricos acordes a las necesidades de los estudiantes en nuestro contexto educativo, favoreciendo una visión de ciencia flexible, humana, sujeta a crisis y tensiones sociales, económicas y científicas.

El diseño y la elaboración de una estrategia didáctica son elementos indispensables para la organización e introducción de propuestas alternativas para la enseñanza y el aprendizaje de las ciencias, permitiendo pensar qué enseñar, cómo hacerlo, para qué, qué recursos se puede usar, cómo y qué evaluar. Estas preguntas, entre otras, son la guía que en la articulación de una propuesta de unidad didáctica (Hernández, 2011) logrará generar transformaciones en las concepciones alternativas acerca de la ciencia entre los estudiantes sujetos de estudio y aportará significativamente a los procesos de transposición didáctica necesarios para llevar al aula la ciencia que permitirá, desde la dinámica escolar, estimular los procesos de formación de futuros científicos. 


\section{Referencias}

Betancur Florez, P. A. (2008). La Incidencia de la Historia y la Epistemología en la Enseñanza del Concepto de ADN (Tesis de licenciatura). Universidad de Antioquia, Colombia.

Borgui, B. (2010). El patrimonio de la historia y su uso didáctico. Investigación en la Escuela, 70, 89-100.

Bugallo Rodríguez, A. (1995). La Didáctica de la Genética: Revisión Bibliográfica. Revista Enseñanza de las Ciencias, 13(3), 379-385.

Carrasco, C. J. G. (2014). Pensamiento histórico y contenidos disciplinares en los libros de texto. Un análisis exploratorio de la Edad Moderna en $2^{\circ}$ de la ESO. Ensayos: Revista de la Facultad de Educación de Albacete, 29(1), 131-158.

Carrasco, C. J. G., Molina, J. O., \& Puche, S. M. (2014). Aprender a pensar históricamente. Retos para la historia en el siglo XXI. Tempo e Argumento, 6(11), 05-27.

Deulofeu, J., Márquez, C., \& Samartí, N. (2010). Formar profesores de secundaria. Cuadernos de Pedagogía, 404, 80-84.

Gagliardi, R. (1988). Cómo utilizar la Historia de las Ciencias en la enseñanza de las ciencias. Enseñanza de las Ciencias, 6(3), 291-296.

Gagliardi, R., \& Giordan, A. (1986). La Historia de las Ciencias, una herramienta para la enseñanza. Enseñanza de las Ciencias, 4(3), 253258 .

Gil Pérez, D. (1993). Contribución de la Historia y la Filosofía de las Ciencias al desarrollo de un modelo de enseñanza/aprendizaje como investigación. Enseñanza de las Ciencias, 11(2), 297-212.

Guevara Pardo, G. (2004). ADN: Historia de un éxito científico. Revista Colombiana de la Historia de la Ciencia, 3(10-11), 9-40.

Hernández, R. (2011). El diseño de una unidad didáctica: un ejercicio docente de continua reflexión. Colombia Entre Comillas, 14, 81-92.

Izquierdo, M. (Abril de 1996). Relación entre la Historia y la Filosofía de la Ciencia y la enseñanza de las ciencias. Revista Alambique: Didáctica de las Ciencias Experimentales y Sociales, 3(8), 7-21. 
Martínez, N., Valls, R., \& Pineda, F. (2009). El uso del libro de texto de Historia de España en Bachillerato: diez años de estudio, 1993-2003, y dos reformas (LGE-LOGSE). Didáctica de las Ciencias Experimentales y Sociales, 23, 3-35.

Matthews, M. (1994). Historia, Filosofía y Enseñanza de las Ciencias: La aproximación actual. Enseñanza de las Ciencias, 12(2), 255-277.

Merlano, A. (2013). Paradigmas emergentes de la ciencia y su impacto en la administración del siglo XXI. Cuadernos de Administración, 15(23), 21-38.

Ortiz Hidalgo, C. (2003). Encontramos el secreto de la vida. 50 años del descubrimiento de la estructura del ADN. Anales Médicos, 48(3), 177188 .

Prieto, J. A. P., Carrasco, C. J. G., \& Martínez, P. M. (2013). El uso de fuentes primarias en el aula y el desarrollo del pensamiento histórico y social: Una experiencia en Bachillerato. Clío: History and History Teaching, 39, 34-14.

Roca Tort, M., Sanmartí, N., \& Márquez, C. (2013). Las preguntas de los alumnos: una propuesta de análisis. Enseñanza de las Ciencias, 31(1), 95-114.

Sáiz Serrano, J. (2013). Alfabetización histórica y competencias básicas en libros de texto de historia y en aprendizajes de estudiantes. Didáctica de las Ciencias Experimentales y Sociales, 27, 37-64.

Sanmartí, N. (2000). El diseño de unidades didácticas. En F. Perales Palacios y P. Cañal de León, Didáctica de las Ciencias Experimentales. Barcelona, España: Editorial Marfil (pp. 239-265).

Solbes, J., \& Traver, M. (1996). La utilización de la Historia de las Ciencias en la enseñanza de la Física y la Química. Enseñanza de las Ciencias, 14(1), 103-112.

Solbes, J., \& Traver, M. (2001). Resultados obtenidos introduciendo Historia de la Ciencia en las clases de Física y Química: Mejora de la imagen de la ciencia y desarrollo de actitudes positivas. Enseñanza de las Ciencias, 19(1), 151-162. 
Valcárcel, N. M., González, X. M. S., \& Llavador, J. B. (2006). Los profesores de Historia y la enseñanza de la Historia en España. Una investigación a partir de los recuerdos de los alumnos. Enseñanza de las Ciencias Sociales, 5, 55-71.

Vázquez, A., Acevedo, J. A., Manassero, M. A., \& Acevedo, P. (2001). Cuatro paradigmas básicos sobre la naturaleza de las ciencias. Argumentos de Razón Técnica: Revista Española de Ciencia, Tecnología y Sociedad, y Filosofia de la Tecnología, 4, 135-176.

Vicente, M. (10 de agosto de 2008). Miod. Un lugar para la ciencia y la tecnología. Recuperado http://www.madrimasd.org/blogs/ microbiologia/2008/08/10/98464 


\section{FUNDACIÓN UNIVERSITARIA AUTÓNOMA DE COLOMBIA PROYECTO DE INVESTIGACIÓN: "LA ENSEÑANZA DEL ADN DESDE UN ENFOQUE HISTÓRICO CON ESTUDIANTES DE EDUCACIÓN BÁSICA SECUNDARIA Y MEDIA VINCULADOS AL SECTOR PÚBLICO"}

Este instrumento tiene como objetivo identificar cuál es tu opinión frente a las siguientes afirmaciones. Marca con una X la opción que consideres se acerca más a tu punto de vista de acuerdo con la siguiente tabla:

\begin{tabular}{|c|c|c|c|}
\hline Muy de acuerdo & De acuerdo & En desacuerdo & Muy en desacuerdo \\
\hline 1 & 2 & 3 & 4 \\
\hline
\end{tabular}

\begin{tabular}{|c|c|c|c|c|}
\hline ÍTEM & 1 & 2 & 3 & 4 \\
\hline $\begin{array}{l}\text { 1. Los resultados de la investigación científica no se ponen en duda, ya que son el resultado } \\
\text { de un proceso riguroso que les da validez. }\end{array}$ & & & & \\
\hline $\begin{array}{l}\text { 2. Los procesos realizados en la investigación científica tienen más importancia que los } \\
\text { resultados obtenidos. }\end{array}$ & & & & \\
\hline $\begin{array}{l}\text { 3. Las verdades en la ciencia son producto de un proceso lógico que dan cuenta de la reali- } \\
\text { dad del mundo que nos rodea. }\end{array}$ & & & & \\
\hline 4. Los avances en la ciencia son el resultado de un proceso científico, histórico y social. & & & & \\
\hline $\begin{array}{l}\text { 5. El trabajo científico se lleva a cabo en el laboratorio, y es allí donde se produce el } \\
\text { conocimiento en la ciencia. }\end{array}$ & & & & \\
\hline $\begin{array}{l}\text { 6. El conocimiento científico es verdadero porque los científicos explican los hechos del } \\
\text { mundo. }\end{array}$ & & & & \\
\hline 7. Las teorías científicas son el resultado de estudiar y analizar hechos sorprendentes. & & & & \\
\hline 8. La ciencia es una actividad humana que permite conocer el mundo natural y social. & & & & \\
\hline $\begin{array}{l}\text { 9. El éxito de la ciencia radica en la aplicación del método científico, que es ordenado, } \\
\text { riguroso y garantiza llegar a la verdad. }\end{array}$ & & & & \\
\hline $\begin{array}{l}\text { 10. Uno de los objetivos de la ciencia es explicar los fenómenos naturales para poder } \\
\text { controlar lo que nos rodea. }\end{array}$ & & & & \\
\hline 11. La explicación científica de un fenómeno natural obedece a un exclusivo punto de vista & & & & \\
\hline 12. Los conocimientos que se tienen sobre un fenómeno siempre son observables. & & & & \\
\hline $\begin{array}{l}\text { 13. Los instrumentos y materiales de laboratorio son recursos indispensables para la gener- } \\
\text { ación de conocimiento científico. }\end{array}$ & & & & \\
\hline 14. La ciencia puede predecir con exactitud el funcionamiento del mundo natural. & & & & \\
\hline $\begin{array}{l}\text { 15. Las investigaciones científicas se ven influenciadas por creencias religiosas, intereses } \\
\text { económicos, políticos y sociales. }\end{array}$ & & & & \\
\hline $\begin{array}{l}\text { 16. Para generar conocimiento científico es necesario relacionar la ciencia, la tecnología y } \\
\text { la sociedad. }\end{array}$ & & & & \\
\hline
\end{tabular}




\section{Anexo B.}

\section{OSOS POLARES, LOS REYES DEL HIELO}

\section{Aíslan por primera vez ADN de oso polar de una huella en la nieve}

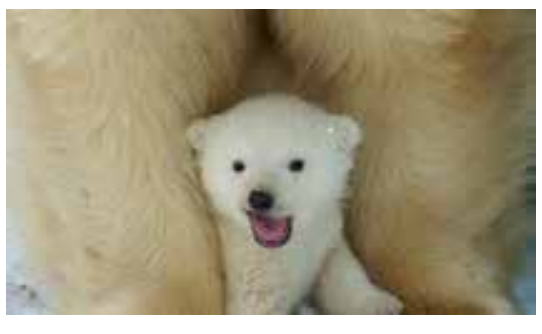

Un equipo de científicos franceses, en colaboración con WWF (Fondo Mundial para la Naturaleza), ha conseguido aislar por primera vez ADN de oso polar de una huella en la nieve. Los científicos analizaron dos muestras de agua tomadas de las pisadas del plantígrado, recogidas a principios de este año durante la expedición de WWF-Canon y del Instituto Polar Noruego al archipiélago de Svalbard. Según Eva Bellemain, líder del equipo investigador, "no solo encontramos el ADN del oso, sino también el de una foca y una gaviota. El equipo de WWF que recogió las muestras pudo ver al oso cazando a la foca y, después, cómo varias gaviotas aparecían en el lugar para intentar participar en el festín, así que una sola huella da fe de toda la historia".

En un entorno tan lejano, aislado e inmenso como el Océano Ártico, que además está cambiando a gran velocidad, supone un gran reto mantener información actualizada y precisa sobre las poblaciones de oso polar. En abril de este año, un equipo de WWF-Canon se embarcó con el Instituto Polar Noruego en una expedición científica por el archipiélago de Svalbard (Noruega), para investigar cómo está afectando el cambio climático a esta región del mundo.

"Este método sería una herramienta muy útil para la biología de la conservación", dice Arnaud Lyet, de WWF. "En la actualidad, los científicos usan técnicas muy caras e invasivas para estudiar el estado de las poblaciones salvajes de especies como el oso polar. Tomando ADN de huellas, podríamos reducir notablemente el presupuesto necesario para investigar, con lo que 
sería más accesible estudiar las poblaciones de fauna". El equipo espera perfeccionar el análisis del ADN de oso polar para obtener más información sobre el animal. También se trata de descubrir si el método puede aplicarse a otras especies tan esquivas y difíciles de alcanzar como los osos polares.

Recuperado de: http://www.muyinteresante.es/naturaleza/articulo/aislan-porprimera-vez-adn-de-oso-polar-de-una-huella-en-la-nieve-601409668243

\section{ACTIVIDAD}

De acuerdo con la información anterior, responda las siguientes preguntas:

1. Teniendo en cuenta la lectura, ¿a qué se hace referencia cuando se habla de ADN?

2. ¿Qué encontraron los científicos en las huellas del oso?

3. ¿Por qué los científicos se interesaron en el ADN del oso?

4. Haga un dibujo que represente la idea que tiene usted de ADN. 


\section{Anexo C.}

\section{OSOS POLARES, LOS REYES DEL HIELO}

\section{Aíslan por primera vez ADN de oso polar de una huella en la nieve}

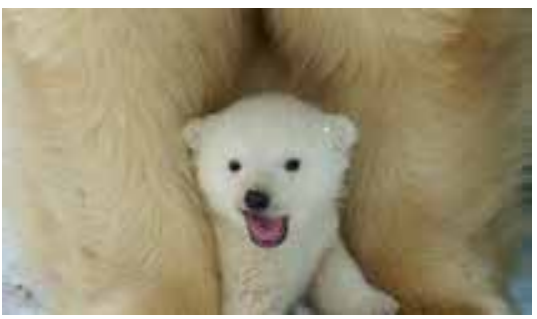

Un equipo de científicos franceses, en colaboración con WWF (Fondo Mundial para la Naturaleza), ha conseguido aislar por primera vez ADN de oso polar de una huella en la nieve. Los científicos analizaron dos muestras de agua tomadas de las pisadas del plantígrado, recogidas a principios de este año durante la expedición de WWF-Canon y del Instituto Polar Noruego al archipiélago de Svalbard. Según Eva Bellemain, líder del equipo investigador, "no solo encontramos el ADN del oso, sino también el de una foca y una gaviota. El equipo de WWF que recogió las muestras pudo ver al oso cazando a la foca y, después, cómo varias gaviotas aparecían en el lugar para intentar participar en el festín, así que una sola huella da fe de toda la historia".

En un entorno tan lejano, aislado e inmenso como el Océano Ártico, que además está cambiando a gran velocidad, supone un gran reto mantener información actualizada y precisa sobre las poblaciones de oso polar. En abril de este año, un equipo de WWF-Canon se embarcó con el Instituto Polar Noruego en una expedición científica por el archipiélago de Svalbard (Noruega), para investigar cómo está afectando el cambio climático a esta región del mundo.

"Este método sería una herramienta muy útil para la biología de la conservación", dice Arnaud Lyet, de WWF. "En la actualidad, los científicos usan técnicas muy caras e invasivas para estudiar el estado de las poblaciones salvajes de especies como el oso polar. Tomando ADN de huellas, podríamos reducir notablemente el presupuesto necesario para investigar, con lo que 
sería más accesible estudiar las poblaciones de fauna". El equipo espera perfeccionar el análisis del ADN de oso polar para obtener más información sobre el animal. También se trata de descubrir si el método puede aplicarse a otras especies tan esquivas y difíciles de alcanzar como los osos polares.

Recuperado de: http://www.muyinteresante.es/naturaleza/articulo/aislan-porprimera-vez-adn-de-oso-polar-de-una-huella-en-la-nieve-601409668243

\section{ACTIVIDAD}

De acuerdo con la información anterior, responda las siguientes preguntas:

1. Describa, según el artículo, cuál fue el proceso que siguieron los científicos para extraer el ADN a partir de la huella del oso.

2. ¿Qué importancia tiene conocer la información genética de estos organismos?

3. Según lo presentado en el artículo y sus conocimientos, haga un esquema que represente la molécula del ADN y sus componentes. 